\title{
The Prevention of Adolescent Depression
}

Tracy R.G. Gladstone, Ph.D' ${ }^{1}$, William R. Beardslee, MD², and Erin E. O'Connor, BA ${ }^{3}$

${ }^{1}$ Wellesley Centers for Women, Wellesley College, Children's Hospital, Boston MA; Judge Baker Children's Center, Boston MA; tgladsto@wellesley.edu

${ }^{2}$ Children's Hospital, Boston MA; Judge Baker Children's Center, Boston MA; william.beardslee@childrens.harvard.edu

3Judge Baker Children's Center, Boston MA; eoconnor@jbcc.harvard.edu

\section{Synopsis}

This article provides a conceptual framework for research on the prevention of depression in youth and reviews the recent literature on prevention efforts targeting children and adolescents. Prevention efforts should target both specific and non-specific risk factors, enhance protective factors, use a developmental approach, and target selective and/or indicated samples. In general, a review of the literature indicates that prevention programs utilizing cognitive behavioral and/or interpersonal approaches, and family-based prevention strategies, are most helpful. Overall, it appears that there is reason for hope regarding the role of interventions in preventing depressive disorders in youth. Several new directions for future research on the prevention of depression in youth were outlined.

\section{Keywords}

depression; prevention; intervention; adolescent

Depression is the most common psychiatric disorder in the United States, with over $16 \%$ of the U.S. population reporting a major depressive episode (MDD) during their lifetime [1]. It is one of the leading causes of morbidity and mortality in the world today [2], and places a significant economic burden on society [3,4]. Depression is among the most treatable mental disorders, yet it remains a chronic illness, with $85 \%$ of people who experience a single episode of depression experiencing another episode within 15 years [5].

In recent years, researchers and policy makers have recognized the importance of focusing on prevention efforts for depression. Prevention requires a paradigm shift from traditional disease models, in which symptoms are treated when they emerge, to a proactive focus on mental health and on maximizing protective factors while reducing risk factors for mental illness [6]. In this article, we will review depression prevention efforts that aim to promote mental health and prevent the onset of depressive disorder in children and adolescents. We

(C) 2010 Elsevier Inc. All rights reserved.

Corresponding Author: William R. Beardslee, MD, Director, Baer Prevention Initiatives and Chairman Emeritus, Department of Psychiatry, Children's Hospital Boston, Gardner/Monks Professor of Child Psychiatry, Harvard Medical School, 21 Autumn Street, Suite 130.2, Boston, Massachusetts 02215, Tel: 617-919-4629 Fax: 617-730-0759, william.beardslee@ childrens.harvard.edu.

Publisher's Disclaimer: This is a PDF file of an unedited manuscript that has been accepted for publication. As a service to our customers we are providing this early version of the manuscript. The manuscript will undergo copyediting, typesetting, and review of the resulting proof before it is published in its final citable form. Please note that during the production process errors may be discovered which could affect the content, and all legal disclaimers that apply to the journal pertain. 
will begin by reviewing the epidemiology of youth depression, and will then outline a conceptual framework for depression prevention research. We will then review the research on depression prevention programs for youth. Finally, we will discuss directions for future research, and key issues to consider when developing and evaluating depression prevention efforts.

\section{Epidemiology of Youth Depression}

Like depression in adulthood, youth depression is quite common [7]. One-year prevalence rates for MDD are about 2\% in childhood and range from $4 \%$ to $7 \%$ in adolescence [8]. According to the National Comorbidity Survey (NCS) [9], the lifetime prevalence of MDD in adolescents aged 15 to 18 years is $14 \%$, and an estimated $20 \%$ of adolescents will have had a depressive disorder by the time they are 18 years old [10,11]. Point prevalence rates of depression during adolescence range from 4 to- $7 \%$, and the average age for first onset of depression is 15 years [12]. One-half of first episodes of depression occur during adolescence [13], and early onset depression is associated with a chronic, episodic course of illness [8]. Although successful treatments for youth depression have been explored, such as antidepressants, cognitive behavioral interventions, and interpersonal psychotherapy, such treatments have been found to work for only about $50 \%$ to $60 \%$ of cases under controlled research conditions [14].

Similar to adult depression, adolescent depression frequently is persistent and recurring $[7,10,11]$. Twelve percent of children will relapse within 1 year, $40 \%$ will relapse within 2 years, and $75 \%$ will experience a second episode within 5 years $[12,15,16]$. Adolescent depression is associated with negative long-term functional and psychiatric outcomes, including impairment in school, work, interpersonal relationships, and substance abuse [1723]. Of particular note is the association between adolescent depression and suicidal behavior. Suicide is the third leading cause of death in adolescents [24]. Over a 1-year period, $13.8 \%$ of adolescents in the United States reported seriously considering suicide, $10.9 \%$ had made suicidal plans, and $6.3 \%$ reported making a suicide attempt [25].

Evidence-based treatments for youth depression, such as cognitive-behavioral therapy and interpersonal approaches, are associated with benefits that, for some, persist over time [26,27]. However, most depressed youth do not receive treatment for depressive symptoms or disorder [28]. When they do receive treatment, although many adolescents respond well to cognitive-behavioral treatment approaches, about half of the depressed children who respond well relapse within 2 years of terminating treatment [29]. Likewise, even adolescents who respond well to combined treatments for youth depression (e.g., cognitive behavioral + medication), often experience residual symptoms of depression. Only $37 \%$ of depressed youth who receive combined treatment are no longer depressed by 12 weeks [30]. Finally, recent data suggest that duration of depression moderates treatment outcome, such that the longer the duration of a depressive episode, the less likely it is to respond to evidence-based treatments [31]. Overall, while treatment for youth depression is important and can be beneficial, many who receive treatment for depression do not respond, have residual symptoms, or experience relapses of disorder [32-35].

Given the high prevalence and costs of youth depression, the connection between early onset depression, and recurrence of the disorder in adulthood, the impairment associated with youth depression, and the difficulty in treating depression once it has developed, efforts to prevent depression are warranted. The importance of preventing depressive disorder through the development and evaluation of preventive interventions was highlighted by the Institute of Medicine (IOM) Report [6], Preventing Mental Disorders [36], and has been emphasized by numerous recent expert panels [37,38]. The IOM report defined prevention as 
interventions that occur before the onset of the disorder, and that are designed to prevent the occurrence of the disorder. Indeed, prevention may be the key to decreasing the burden of adolescent and adult depression on society, and may be more cost-effective and less distressing than waiting for the condition to appear and then trying to treat a full depressive episode.

\section{Conceptual Framework for Depression Prevention Research}

In the past several decades, research on the prevention of youth depression has blossomed, and as a result, we now know much more about ways to maximize the efficacy of prevention efforts. That is, we know more about the variables to target, the timing of interventions, and the samples that will be most likely to benefit from depression prevention efforts.

\section{Risk/Protective Factors}

A key early stage of prevention research involves understanding specific and non-specific risk and protective factors, as prevention efforts that work benefit from a focus on decreasing risk factors and enhancing protective factors for a particular disorder. Understanding the risk and protective factors for depression enables researchers to make careful choices about the prevention strategies they use.

Specific risk factors-Specific risk factors are those factors that have been associated with increased risk for youth depression in empirical investigations. Specific risk factors for adolescent depression include having low self-esteem, being female, negative body image, low social support, a negative cognitive style, and ineffective coping [39]. In the case of youth depression, the strongest risk factor for the development of depression, above and beyond the variance accounted for by other risk factors, is having a parent with depressive illness [40]. Offspring of depressed parents are at about a two- to four-fold increased risk of developing depressive disorders, and over half of the parents bringing their depressed adolescents for services themselves have current mood disorders [40]. Research in the past 20 years suggests that children who grow up with depressed parents have more internalizing disorders such as depression and anxiety, more externalizing disorders such as conduct disorder and attention deficit disorder [41], more cognitive delays and academic difficulties, and more social difficulties [40]. It is important to note that not all children of depressed parents become depressed, and many children of depressed parents are resilient and do well over time [42]. Thus, many depression prevention efforts in youth have targeted either those with symptoms or those whose parents have depression.

Nonspecific risk factors-A comprehensive approach to the prevention of depression involves addressing both specific and nonspecific risk factors. Nonspecific risk factors are associated with increased risk for a range of disorders including depression. Nonspecific risk factors that are documented to increase rates of youth depression include poverty, exposure to violence, social isolation, child maltreatment, and family breakup [39]. In fact, reducing the burdens of poverty, exposure to violence, child maltreatment, and other forms of family instability may play an important role in the reduction of depressive disorders in youth [39].

For example, both poverty and child maltreatment have been associated with many negative outcomes. Specifically, a recent study of a subsample of the United States National Collaborative Perinatal Project examined the relation between lower socioeconomic status (SES) in families of young children and later rates of depression [43]. Lifetime risk for depression was related to occupational level of the parents at birth. Subjects with parents of lower SES backgrounds had significantly increased lifetime rates of depression. In particular, having a family history of mental illness was associated with later depression, while adult educational attainment and depression were inversely related. Also, in a 
prospective longitudinal study of 676 maltreated children, and 520 nonabused and nonneglected control subjects, Widom et al. [44] found a significant relation between child physical abuse and increased risk for lifetime MDD, and between child neglect and increased risk for current MDD. Research on the additive effects of childhood risk factors suggests that addressing both specific and nonspecific risk factors together may have the best chance of preventing disorder [6,39].

Resilience and protective factors-Although the presence of both specific and nonspecific risk factors does indicate an increased risk for youth depression, it is important to remember that not all children and adolescents who are exposed to these risk factors develop disorder. In fact, many children who are exposed to risk factors for depression also have protective factors and exhibit resilience, which means that they have characteristics that decrease the likelihood of developing depression [39]. Protective factors for youth depression include the presence of supportive adults, strong family relationships, strong peer relationships, coping skills, and skills in emotion regulation [39]. In a specific study of children of depressed parents [42], the authors studied a subset of resilient youth whose parents had experienced depression. Within the youth, they found that several factors contributed to resilience, including a focus on accomplishing age-appropriate developmental tasks, on relationships, and on understanding their parents' illness. Within the parents, they found that resilience was associated with a commitment to parenting despite depression, and a commitment to relationships.

\section{Timing of Intervention Delivery}

Most mental disorders have their onsets during childhood or adolescence. In fact, $75 \%$ of all adult mental health disorders have their onset by age 24, and 50\% of adult disorders have an onset by age 14 [6]. Further, data on the onset of mental disorders suggests that early symptoms of disorder emerge a few years before full diagnostic criteria are met (see Figure 1) [6].

Successful prevention efforts use a developmental approach, positioning the intervention in the developmental epoch preceding or during the age of peak incidence. Data on the onset of disorder suggest that, during childhood and adolescence, there may be opportune developmental windows in which to intervene to maximize the benefits of intervention [6]. For example, while the mean age of first diagnosis for depression is 15 [12], symptoms of depression generally emerge 3 to- 4 years earlier [6]. Successful depression prevention programs target the developmental window from ages 11 to-15, when symptoms are present but before the onset of full-blown disorder [6].

\section{Definition of Prevention and Sample Definition}

According to the IOM (1994) report [6], there are three categories of preventive interventions: universal, selective, and indicated. Universal preventive interventions target the general public or community regardless of risk. An example of a universal prevention program is a curriculum that teaches about the dangers of substance abuse to all high school freshmen in the community. Selective prevention programs target members of a subgroup who are at higher risk for disorder, such as children of depressed parents. Finally, indicated prevention programs target all people who display subclinical signs or symptoms of a given disorder. An example of an indicated prevention program is a curriculum that teaches depression prevention strategies to teens with subclinical depressive symptoms.

Horowitz and Garber [45] conducted a meta-analysis of 30 depression prevention studies for youth and found that, at post-intervention, selective prevention programs, such as those focusing on children of depressed parents, were more effective than universal programs that 
targeted all high school students district-wide. They also found that selective and indicated prevention programs were more effective than universal programs at 6 month follow-up. Although targeted prevention programs appear to be more effective than universal programs, several studies have demonstrated favorable outcomes using universal programs.

\section{Review of Depression Prevention Efforts for Youth}

To date, researchers who have studied the effects of preventive interventions on depression in youth generally have based their prevention strategies on cognitive-behavioral and/or interpersonal approaches [46]. These approaches have been found to be helpful in the treatment of depression [47], and recently have been evaluated to determine whether they may be useful in preventing youth depression. Below we review recent research on depression prevention efforts for youth, using the IOM categories for preventive interventions. We will begin by reviewing research on universal prevention programs, followed by a review of selective prevention programs and then indicated prevention programs.

\section{Universal Prevention Programs}

School based-One successful universal prevention program was evaluated by Spence and colleagues, who report data from a universal, school-based prevention program targeting 1500 youth aged 12 to 14 years attending high school in Queensland, Australia $[48,49]$.

Schools were assigned randomly to the Problem Solving for Life (PSFL) intervention or the MC (the school-as-usual condition). Participants were evaluated for depressive symptoms as well as a range of other risk variables at baseline (pre-intervention), post-intervention, and again at a 12-month follow-up. A group of high-risk participants was identified at baseline based on elevated scores on measures of depressive symptomatology. The PSFL intervention consists of eight 45-to 50-minute weekly sessions that focus on teaching cognitive restructuring and problem solving. The program is implemented by classroom teachers who are trained in the program's theory, content, and implementation techniques during a 6-hour training session.

Overall, at post-intervention, students assigned to the PSFL condition demonstrated reduced symptoms of depression, relative to students assigned to the MC condition, and a greater number of high-risk students in the PSFL condition were no longer classified as high risk. However, these group differences were not maintained. Moreover, survival analyses revealed there was no significant group difference in the incidence of depressive disorders in high-risk participants over time. This work suggests that prevention programs can be delivered by teachers with fidelity, that youth may be receptive to interventions, and that this intervention can yield short-term effects in reducing depressive symptoms in Australia. However, this work also highlights the importance of long-term follow-up and the difficulties of using a universal prevention approach to reduce depression diagnoses.

Another universal school-based program aimed at preventing depression in adolescence was evaluated by Shochet et al. [50]. Students in grade $9(n=260)$ were assigned to one of three different groups: Resourceful Adolescent Program-Adolescents (RAP-A), Resourceful Adolescent Program-Family (RAP-F), and Adolescent Watch. RAP-A was part of an 11session program as part of the school curriculum; it focused on building resilience in the students. The RAP-F program was identical to RAP-A, but in RAP-F, the students' parents were invited to participate in a parent program consisting of 3 different sessions. The Adolescent Watch program (AW) was the comparison group in which the adolescents only completed measures of depressive symptoms and hopelessness. 
Results indicated that the two intervention groups (RAP-A and RAP-F) did not differ from one another, but did differ from the comparison group (AW). For the two intervention groups, there were significant reductions in depressive symptoms and hopelessness scores that were maintained at a 10-month follow-up. For the AW program, there were no significant changes in scores post-intervention. These results indicate that the addition of the parent component to the RAP-A program did not significantly increase the program's efficacy.

Merry and colleagues [51] evaluated the efficacy of another school-based program, the RAP-Kiwi intervention, based on the RAP program by Shochet et al. [50], as described above. This intervention is derived from cognitive behavioral therapy and consists of 11sessions in which principles of cognitive-behavioral and interpersonal therapy are incorporated. The intervention used by Merry targeted students $(n=392)$ aged $13-15$, and each student was randomized to the intervention (RAP-Kiwi) $(n=207)$ or placebo program $(\mathrm{n}=185)$. The placebo program contained elements focusing on having fun, such as arts and crafts, rather than elements that have been identified as aiding in preventing depression.

Results indicated that depressive symptoms were significantly reduced by the RAP-Kiwi program, more so than the placebo program. Categorical analyses indicated that there was an absolute risk reduction of $3 \%$ for the RAP-Kiwi group. These results remained consistent at an 18-month follow-up, with the RAP-Kiwi group having a greater mean difference in depression scores $(M=1.55)$ than the placebo group $(M=1.31)$. This study indicates that a school-based universal depression prevention program administered by teachers is effective in reducing depressive symptoms in adolescents, both in the short-term and in the long-term.

Cognitive-behavioral-Horowitz and colleagues [52] evaluated a universal group cognitive-behavioral program (CB) for preventing depressive symptoms in adolescence that was based on Clarke's Coping With Stress program [53]. High school students enrolled in wellness classes $(n=380)$ were randomly assigned to one of three programs: the Cognitive Behavioral Program (CB), the Interpersonal Psychotherapy-Adolescent Skills Training Program (IPT-AST), or a no-intervention control. Eight group leaders, all of whom were trained master's-level clinical psychology graduate students or recent clinical psychology $\mathrm{PhDs}$, and eight co-leaders, all of whom were clinical graduate students or undergraduate honor students, led the groups.

The results indicated that the difference between the CB and IPT-AST groups were largest for the students who had higher levels of depressive symptoms at baseline. These data indicate that the prevention programs were more effective for participants who were at risk for depression based on elevated depressive symptoms scores at baseline, consistent with an indicated prevention approach.

\section{Selective Prevention Programs}

School-based-The Penn-Resiliency Program (PRP) [54], perhaps the most widely evaluated depression prevention program for youth [55], was developed to target cognitive and behavioral risk factors for depression in school-aged children. Based on cognitive behavioral therapy, PRP is a school-based program that teaches participants the connection between life events, their beliefs about those events, and the emotional consequences of their interpretations. The manualized PRP curriculum is generally administered by trained school personnel during the school day and consists of twelve 90- to 120-minute group sessions.

PRP has been evaluated empirically over several years with children and adolescents of varying ages and from varying ethnic and cultural backgrounds, both in universal and in targeted prevention studies [55-56]. Overall, these studies have found that, relative to 
participants in the control conditions, participants in PRP experienced reduced depressive symptoms over follow-up intervals ranging from 6 months to two years. In one such prevention study, conducted in primary care clinics within a Health Maintenance Organization (HMO), children aged 11 and 12 years identified as high risk based on a selfreport questionnaire were invited to participate. Although PRP was found to improve explanatory style (that is, world view) for positive events, and reduced depressive symptoms for girls only, no overall preventive effects of PRP were found for depression diagnoses. Gillham and colleagues [57] examined the efficacy of adding a parent intervention component to the PRP. The parent intervention component was designed to increase parents' overall resilience as well as their parenting skills. Results indicated that students in the PRPplus-parent group reported lower levels of depressive symptoms $(p=.05)$ and anxiety symptoms $(p=.01)$ over the follow-up period, relative to usual care. These findings have important clinical implications. First, it appears that this intervention prevents both depressive symptoms and anxiety symptoms, which have been found to be potential risk factors for youth depression [57]. Second, these findings support the involvement of parents in preventing youth depression.

The PRP has further been evaluated with African American and Latino children who were at risk due to their low-income status [58]. The Latino children reported significantly fewer depressive symptoms $(p=.001)$ than did the children in the control group, and these results were consistent at the 6-month follow-up. Furthermore, Latino children in the prevention group had fewer negative automatic thoughts $(p=.01)$ and feelings of hopelessness $(p=10)$. For the African American children however, there were no significant differences in the number of reported depressive symptoms between the intervention and control groups. Similarly, there were no significant differences in negative automatic thoughts or hopelessness between the two groups of African American children. Importantly however, the prevention children did show significant improvement over the course of the intervention, but the results were not significantly different from the no-treatment, control condition. These results were found to be consistent at a 2-year follow-up [59].

Cognitive-Behavioral-Based on research by Lewinsohn et al. [60] examining risk for depression in adolescents, Clarke and colleagues [61] developed the Coping With Stress (CWS) course, a manual-based psychoeducational group program targeting adolescents at risk for the development of depressive disorders. The CWS program aims to help at-risk teens gain control over negative moods, resolve conflicts that arise at home and with peers, and alter maladaptive thought patterns. The CWS program targets teens aged 13 to 17 years and is delivered by trained mental health professionals (for example, social workers and psychologists) in a group setting.

Clarke et al. [61] examined the effectiveness of the CWS program, relative to a Usual-Care Control condition (UC), in a randomized-controlled trial (RCT) of 94 adolescent offspring of adults treated for depression in a HMO. Eligible teens had to have subdiagnostic depressive symptoms and/or a history of mood disorder, and a parent with a significant depressive disorder. Results indicated that, relative to teens assigned to the UC, teens in the CWS program reported fewer depressive symptoms, fewer symptoms of suicide, and better overall functioning. At 12-month follow-up, $9.3 \%$ of the teens in the CWS program met diagnostic criteria for major depression, compared with $28.8 \%$ of the teens in the UC control $(p=0.003)$. Although the significant preventive effect persisted across a 24-month followup interval, the magnitude of the effect diminished ( $p=0.02$ at 18 months; $p=0.05$ at 24 months).

A 4-site effectiveness study led by Judy Garber [62] is being conducted using a variant of the CWS program developed by Clarke and colleagues [61]. Known as the Prevention of 
Depression in At-Risk Adolescents study, Garber and colleagues have modified the CWS program to include 8 weekly and 6 monthly continuation sessions, and have recruited 316 teens (nearly 80 from each site) who have been assigned randomly to the Cognitive Behavioral Prevention Program (CBP) or the UC condition [62]. Results indicate that, through the 8-month follow-up assessment conducted at the completion of the monthly continuation sessions, significantly fewer teens in the CBP group had a probable or definite episode of depression, compared with adolescents in the UC condition [63]. Moreover, this main intervention effect was moderated by current parental depression at baseline, such that among adolescents whose parents were not depressed at baseline, CBP was much more effective in preventing the incidence of depressive episodes than UC. Among adolescents in both conditions with a currently depressed parent, rates of incident depression were not significantly different from each other [63]. It should be noted that the Clarke and Garber studies are a combination of selective and indicated preventive interventions. That is, the parents have depression (selective prevention), but in those studies, some of the children were also symptomatic (indicated prevention). A long-term follow-up of this sample is currently underway.

Family-based-A number of intervention programs for the prevention of depression in children and adolescents have incorporated the family system as an integral target of intervention. One such study by Compas and colleagues [64] assessed the efficacy of a family cognitive-behavioral preventive intervention aimed at preventing depression in the offspring of parents with a history of depression. The 111 families were randomly assigned to an intervention or control condition. The intervention condition consisted of 8 weekly and 4 monthly sessions with up to 4 families per group, in which both the parents and the children participated. The family cognitive-behavioral intervention was designed to educate families about depressive disorders, help families recognize and deal with stress, promote adaptive coping responses to stress, the improvement of parenting skills, and increasing family awareness of the impact that stress and depression can have on functioning. The families were also assessed at 2-, 6-, and 12-months post intervention.

Results indicated that overall, the family cognitive-behavioral program produced the strongest effects for positive parent and child outcomes, relative to the control condition. The intervention, relative to the control condition, produced significant child benefits in terms of depressive symptoms, anxiety symptoms, and internalizing symptoms with marginally significant effects on externalizing symptoms. Parent depressive symptoms were also significantly less in the intervention group as compared to the control group at all three assessment points.

Beardslee et al. [65] have also developed 2 public health interventions for families when parents are depressed. Beardslee et al.'s approaches emphasize a cognitive orientation and focus on building strengths and resilience in youth. They also focus on the family as a unit of change and aim to increase parents' understanding of depression and the effects of their depression on their spouses and children. In the Beardslee clinician-facilitated intervention approach, six to eight 45- to 90-minute sessions were conducted with a clinician and with individual families, culminating with a family meeting in which the clinician facilitated a family discussion of depression and its effects on the family. The lecture control condition consisted of 2 small group lectures for parents only. Although children did not attend these lecture sessions directly, parents were encouraged to discuss with their children the effects of depression on the family.

Beardslee et al. $[66-68,65,69]$ have examined the efficacy of the Beardslee prevention approaches. In this research, 100 families with parental depression and a nondepressed child aged 8 to 15 years were assigned randomly to either the clinician-facilitated or the lecture 
group condition. The families were assessed at baseline, immediately post intervention, and then at approximately 1-year intervals over several years. Both conditions were associated with positive changes in parents' behaviors and attitudes regarding their children, in general family improvements, and in decreased depressive symptoms in children. However, relative to the lecture group condition, the clinician-facilitated condition was associated with greater understanding by children of their parents' depressive illness, and improved communication between children and parents. Intervention effects were sustained at 2.5- and 4-year followup intervals [65,66]. Moreover, families in which parents reported the most change in behavior and attitude had children who showed the greatest increase in their understanding of their parents' illness, one of the main targets of this preventive intervention.

It is noteworthy that since the development of these intervention approaches, several research groups have adapted the general principles of these programs to new populations and have evaluated these approaches in effectiveness trials. Podorefsky et al. [70] adapted the clinician-facilitated intervention approach for use in a low-income, urban population, and found that families who participated in the intervention reported positive change in family communication, understanding, and focus on the child. They also recently adapted it for use with Latino mothers [71]. Several European countries have developed countrywide programs for children of people with mental illness. Solantaus et al. [72] have developed a successful program in Finland and selected the clinician intervention, as one of several interventions, for widespread use. It proved possible both to adapt it to the Finnish context and to train clinicians in its use [73].

Unlike other researchers examining the prevention of youth depression in teens identified based on their elevated depressive symptoms or family history of depression, Sandler et al. [74] focused on preventing negative outcomes in children at risk based on difficult life circumstances, including parental divorce and bereavement. Sandler's research programs rely on correlational studies that identify protective and vulnerability factors that may be addressed through intervention. Both programs focus on experimental studies that evaluate the effects of these interventions on changing these factors to promote resilience.

Based on research indicating that parental divorce, although common, places children at risk for post-divorce adjustment difficulties, Tein et al. [75] and Wolchik et al. [76] developed and evaluated the New Beginnings Progam (NBP), a preventive intervention for divorced families that consists of 2 components: a mother program and a dual-component program that targeted mothers and children in separate but concurrent intervention approaches. These 2 active intervention programs were contrasted to a self-study literature control program in which, during a 6-week period, mothers and children received written materials pertaining to parental divorce.

In a study of 240 recently (within the past 2 years) divorced families with a female primary residential parent and at least one child aged 9 to 12 years, families were assigned randomly to either the mother program, the dual-component (mother and child) intervention, or the self-study control condition [77]. Overall, the mother program was associated with positive change in the mother-child relationship, discipline, and the child's relationship with the father, relative to families who were assigned to the self-study control condition, although some of these changes were not sustained during the 6-month follow-up. In addition, the mother program was associated with mother and child reports of children's decreased internalizing and externalizing of problems. And, at 6-year follow-up, youths in the dualcomponent intervention, relative to youths in the control condition, tended to have fewer diagnosed mental disorders $(p=0.007)$ [77]. Children in the NBP improved more on total psychiatric symptoms, externalizing problems, substance use, grade point average, and had a reduced number of sexual partners $[77,78]$. 
Sandler et al. [79-82] and Tein et al. [83] have also developed the Family Bereavement Progam (FBP), which aims to prevent mental health problems in bereaved children aged 8 to 16 years and promote resilient outcomes for children and families facing parental loss. The FBP targeted key family-level variables, including: the quality of the caregiver-child relationship; mental health problems in the caregiver; the child's exposure to negative life events; and discipline [80]. The FBP is a 2 component program that includes separate groups for parents and (or) caregivers, and for bereaved children. Sandler et al. [82] evaluated the FBP in an RCT of 156 families in which a parent had died between 4 and 30 months prior to enrollment, and in which neither the surviving parent nor the child (aged 8 to 16 years) were receiving mental health or bereavement services. Families were assigned randomly to either the FBP or to a self-study control program, in which books about grief were distributed to parents and to children at monthly intervals.

Overall, results indicated that, relative to families in the self-study control group, families in the FBP demonstrated improved family and individual risk factors immediately following intervention. However, the FBP was not associated with a change in children's mental health problems at posttest. At 11-month follow-up, the FBP program was found to improve selfreport mental health outcomes for girls, and for children who exhibited more internalizing and externalizing difficulties at baseline. Finally, new program main effects emerged at 6year follow-up for youths' self-esteem and externalizing behaviors [82]. Work by Sandler et al. [74] highlights the importance of intervening with families during times of stress. In addition, this work suggests the possibility that intervention effects may emerge gradually over time, and that the effects of intervention strategies may vary by sex. Presently, Sandler and colleagues are examining longer-term intervention effects and exploring the effects of intervention on clinical diagnoses of depression.

\section{Indicated Prevention Programs}

Internet-based-In recent years, the Internet has joined the ranks of preventative intervention tools as programs have begun to utilize the accessibility and cost-effectiveness of Internet-based programs. Van Voorhees and colleagues [84] have implemented a pilot study of a primary care, Internet-based depression prevention intervention for at-risk adolescents, "Project CATCH-IT." The program combines cognitive-behavioral therapy, behavioral activation, and interpersonal psychotherapy techniques. A family training program was also included in the intervention to enhance family resiliency by targeting and improving parenting skills. The intervention consisted of a primary care interview, followed by the Internet-based intervention, which was followed by an additional primary care interview and data collection, approximately 4- to 6 weeks post-intervention. Preliminary findings indicated that adolescents were willing to engage in the intervention and viewed the program favorably.

Van Voorhees and colleagues [85] further explored the efficacy of internet indicated prevention programs by determining the willingness of adolescents to participate based on the type of primary care physician engagement provided. The participants were randomly assigned to one of two internet-based prevention groups: Brief Advice (BA) + Internet Program, and Motivational Interview (MI) + Internet Program. Participation and satisfaction were measured over a 12 month time period in order to assess the willingness of at-risk adolescents to use an Internet-based prevention of depression program.

Results indicated that the MI group had significantly higher engagement responses to the internet program than did the BA group in terms of total time on site $(p=.03)$, number of sessions $(\mathrm{p}=.04)$, longer duration of session activity on the Internet $(\mathrm{p}=.04)$, and more characters typed into the exercises $(\mathrm{p}=.01)$. Furthermore, the MI group displayed higher trust in their physician $(\mathrm{p}=.05)$ and greater satisfaction in the Internet component relative to 
the BA group $(\mathrm{p}=.01)$. As this study demonstrates, motivational interviews with the primary care physician may encourage adolescent participation in Internet-based prevention programs for depression, allowing for prevention to reach a population that may not be responsive to traditional prevention programs.

Interpersonal-Based on an effective interpersonal psychotherapy treatment program for depressed adolescents $[86,87]$, the IPT-AST program was developed and evaluated for effectiveness in preventing the onset of depressive disorders in high-risk teens. This schoolbased group intervention focuses on psychoeducation regarding depression and prevention, and skill-building that targets interpersonal role disputes, role transitions, and interpersonal deficits. Young et al. [88] report a school-based study of IPT-AST in which 41 primarily Hispanic youth aged 11 to 16 years with elevated scores on a measure of depressive symptoms were assigned randomly to either the intervention group or to a school counseling control group. The IPT-AST intervention included 2 initial individual sessions, followed by 8 weekly 90-minute group sessions. Sessions were conducted during the school day and implemented by school guidance counselors and/or psychologists trained by the research team.

Results indicated that, relative to children in the school counseling control condition, adolescents in the IPT-AST group reported fewer symptoms of depression, controlling for baseline depression scores, and better overall functioning, and these differences were sustained across the 6 month follow-up. In addition, across the 6-month follow-up interval, $3.7 \%$ of the IPT-AST teens met diagnostic criteria for a clinical diagnosis of depression, compared with $28.6 \%$ of the teens assigned to the control group. This difference was marginally significant $(p=0.08)$. While promising, it is concerning that only one-half of eligible youth elected to participate in this program. Nonetheless, this work suggests that it may be possible to prevent depressive disorders with relatively short interventions, and as the investigators themselves have suggested, it may well make sense to combine this approach with more traditional cognitive-behavioral approaches to depression prevention in youth [89].

\section{Summary and Discussion}

The specific depression prevention programs reviewed above share several meaningful characteristics. In general, the content of these interventions was outlined in manuals and based on evidence-based treatment programs for adolescent depression, those implementing the protocols were carefully trained, and fidelity to the intervention protocols was assessed. The interventions were based on an understanding of risk and protective factors for youth depression, generally targeted an opportune developmental window for depression prevention, and were consistent with universal, selective, and indicated prevention models.

Overall, it appears that there is reason for hope regarding the role of interventions in preventing depressive disorders in youth. Certainly it seems that such prevention programs decrease children's levels of depressive symptoms, and as symptoms clearly are forerunners of full-blown episodes, they are an important positive outcome in and of themselves. There is evidence that prevention interventions can produce meaningful family change, and that this change in family functioning can have long-term, positive benefits on children and adolescents.

Our review highlights several directions for future research on the prevention of depression in youth.

1. Given the high cost of depression once it occurs and the promise of the initial studies we have described for selective and indicated prevention, much more 
attention needs to be focused on depression prevention efforts. While none of these programs is ready for widespread dissemination at present, we think that should be the goal over the long-term.

2. We believe that further research will continue to establish an empirical base for the prevention of depression in high-risk youth. Thus, short-term, manual-based preventive interventions for youth at high risk for depression should be considered for widespread use and should be considered core parts of the resources available to clinicians and families at high risk for depression. It is crucially important that future interventions both be assessed for and able to contribute to long-term positive outcomes.

3. Selected and indicated prevention approaches appear to be more effective than universal prevention approaches [46].

4. It is important to attend to moderators of intervention effects. It appears that some intervention programs work better for youth at particularly high risk for depression, as based on individual risk variables and/or family risk. Additional important moderators to consider in future research include sex and exposure to recent stressors $[52,90]$.

5. It is important to consider approaches that can be widely used and easily taught, in addition to more specialized approaches. The family approaches of the Preventive Intervention Project and the development of countrywide programs in Scandinavia emphasize that when good public health interventions are available, they can be widely disseminated.

6. Prevention programs targeting youth depression should include efforts to enhance the family environment. Avenevoli and Merikangas [89] argue that family-based programs are indicated because parental psychopathology is associated with general dysfunction in parental and/or family environment, such that changing the environment of at-risk youth may lower their risk for depression. In fact, family factors may maintain depression in youth [91,92], and family factors have been found to predict outcome and treatment response among depressed children and adolescents. Moreover, adverse family environments are among the most consistent risk factors for adolescent depression [37]. The Preventive Intervention Project, as well as the programs developed by Sandler and colleagues [74], are examples of effective family-based programs. Similar programs targeting the prevention of youth depression are warranted. More generally, the IOM report on prevention emphasized the value of programs that enhance parenting for families.

7. While not the primary focus of this review, careful study of risk factors for depression emphasizes the importance of both specific and non-specific risk factors. In terms of the nonspecific risk factors, attention to poverty, exposure to violence, child sexual abuse, and circumstances in which children are exposed to multiple adversities in childhood are needed. Clearly, we would substantially reduce the illness burden for a wide array of childhood and adolescent difficulties including depression if we more fully assessed these nonspecific risk factors.

8. As more is understood about the underlying neuroscience dimensions of depression, this is likely to suggest effective prevention strategies. For example, if it becomes possible to identify those at highest risk earlier in the course of childhood because of genetic vulnerability, it may well be possible to more effectively target specific prevention approaches.

9. More research is needed on the dissemination phase of prevention research. Efforts to demonstrate the effectiveness of prevention programs need to consider the 
unique needs and experiences of children from different ethnic and cultural groups. [93]

10. There needs to be much greater coordination among efforts for the prevention of depression in children and adolescents. It would be useful if one of the Federal agencies took the lead in coordinating this across the National Institute of Health, and also involving other research resources such as those supported by foundations. Through coordinating different research efforts, it is much more likely that broadly disseminated programs could be identified.

\section{REFERENCES}

1. Kessler RC, Berglund P, Demler O, et al. The epidemiology of major depressive disorder: Results from the National Comorbidity Survey Replication (NCS-R). JAMA. 2003; 289:3095-3105. [PubMed: 12813115]

2. World Health Organization. The global burden of disease. Geneva (CE): WHO Press; 1996.

3. Greenberg PE, Kessler R, Birnbaum H. The economic burden of depression in the United States: how did it change between 1990 and 2000? J Clin Psychiatry. 2003; 64:1465-1475. [PubMed: 14728109]

4. Lynch F, Clarke G. Estimating the economic burden of depression in children and adolescents. Am J Prev Med. 2006; 31:S143-S151. [PubMed: 17175409]

5. Mueller TI, Leon AC, Keller MB, et al. Recurrence after recovery from major depressive disorder during 15 years of observational follow-up. Am J Psychiatry. 1999; 156:1000-1006. [PubMed: 10401442]

6. National Research Council and Institute of Medicine. Prevention Committee. Preventing emotional and behavioral disorders among young people: progress and possibilities. National Academies Press; 2009. [place unknown]

7. Kovacs M. Next steps for research on child and adolescent depression prevention. Am J Prev Med. 2006; 31:S184-S185. [PubMed: 17175413]

8. Costello EJ, Pine DS, Hammen C, et al. Development and natural history of mood disorders. Biol Psychiatry. 2002; 52:529-542. [PubMed: 12361667]

9. Kessler R, Walters EE. Epidemiology of DSM-III-R major depression and minor depression among adolescents and young adults in the National Comorbidity Survey. Depress Anxiety. 1998; 7:3-15. [PubMed: 9592628]

10. Birmaher B, Ryan ND, Brent D, et al. Child and adolescent depression: a review of the past ten years. Part I. J Am Acad Child Adolesc Psychiatry. 1996; 35:1427-1439. [PubMed: 8936909]

11. Birmaher B, Ryan ND, Williamson DE, et al. Child and adolescent depression: a review of the past ten years. Part II. J Am Acad Child Adolesc Psychiatry. 1996; 35:1575-1583. [PubMed: 8973063]

12. Lewinsohn PM, Clarke GN, Seeley JR, et al. Major depression in community adolescents: Age at onset, episode duration, and time to recurrence. J Am Acad Child Adolesc Psychiatry. 1994; 33:809-818. [PubMed: 7598758]

13. Kessler R, Wai CT, Demler O, et al. Prevalence, severity, and comorbidity of 12-month DSM-IV disorders in the National Comorbidity Survey replication. Arch Gen Psychiatry. 2005; 62:617627. [PubMed: 15939839]

14. March JS, Silva S, Petrycki S. Treatment for Adolescents with Depression Study Team. Fluoxetine, cognitive-behavioral therapy, and their combination for adolescents with depression. JAMA. 2004; 292:807-820. [PubMed: 15315995]

15. Kovacs M, Feinberg TL, Crouse-Novak MA, et al. Depressive disorders in childhood: I. A longitudinal prospective study of characteristics and recovery. Arch Gen Psych. I984a; 41:229237.

16. Kovacs M, Feinberg TL, Crouse-Novak MA, et al. A longitudinal prospective study of characteristics and recovery. Arch Gen Psych. 1984b; 41:643-649.

17. Bardone AM, Moffitt T, Caspi A, et al. Adult mental health and social outcomes of adolescent girls with depression and conduct disorder. Dev Psychopathol. 1996; 8:811-829. 
18. Bardone AM, Moffitt T, Caspi A. Adult physical health outcomes of adolescent girls with conduct disorder, depression and anxiety. J Am Acad Child Adolesc Psychiatry. 1998; 37:594-601. [PubMed: 9628079]

19. Lewinsohn PM, Pettit JW, Joiner TE, et al. The symptomatic expression of major depressive disorder in adolescents and young adults. J Abnorm Psychol. 2003; 112:244-253. [PubMed: 12784834]

20. Rao U, Ryan ND, Birmaher B, et al. Unipolar depression in adolescents: clinical outcome in adulthood. J Am Acad Child Adolesc Psychiatry. 1995; 34:566-578. [PubMed: 7775352]

21. Weissman MM, Wolk S, Goldstein RB, et al. Depressed adolescents grown up. JAMA. 1999; 17:7-13.

22. Rubin KH, Both L, Zahn-Waxler C, et al. Dyadic play behaviors of children of well and depressed mothers. Dev Psychopathol. 1991; 3:243-251.

23. Harnish JD, Dodge KA, Valente E. Mother-child interaction quality as a partial mediator of the roles of maternal depressive symptomatology and socioeconomic status in the development of child behavior problems. Child Dev. 1995; 66:739-753. [PubMed: 7789199]

24. Centers for Disease Control and Prevention. Web-based Injury Statistics Query and Reporting System (WISQARS). Atlanta, GA: Centers for Disease Control and Prevention; 2010 [Accessed August 23, 2010]. National Center for Injury Prevention and Control. www.cdc.gov/ncipc/wisqars.

25. Centers for Disease Control and Prevention. Youth Risk Behavior Surveillance-United States 2009. Surveillance Summaries. 2010; 59 SS-5.

26. Clarke G, Hornbrook M, Lynch F, et al. A randomized trial of a group cognitive intervention for preventing depression in adolescent offspring of depressed parents. Arch Gen Psychiatry. 2001; 58:1127-1134. [PubMed: 11735841]

27. Garber J, Clarke G, Weersing VR, et al. Prevention of depression in at-risk adolescents: A randomized controlled trial. JAMA. 2009; 301:2215-2224. [PubMed: 19491183]

28. Kessler RC, McGonagle KA, Zhao S, et al. Lifetime and 12-month prevalence of DSM-III-R psychiatry disorders in the United States. Arch Gen Psychiatry. 1994; 51:8-19. [PubMed: 8279933]

29. Evans, DL.; Foa, EB.; Gur, RE., et al. Treating and preventing adolescent mental health disorders: what we know and what we don't know. New York: Oxford University Press; 2005. Treatment of depression and bipolar disorder; p. 30-54.

30. Kennard BD, Silva SG, Tonev S, et al. Remission and recovery in the Treatment for Adolescents with Depression Study (TADS): Acute and long-term outcomes. J Am Acad Child Adolesc Psychiatry. 2009; 48:186-195. [PubMed: 19127172]

31. Curry J, Rohde P, Simons A. Predictors and moderators of acute outcome in TADS. J Am Acad Child Adolesc Psychiatry. 200; 45:1427-1439. [PubMed: 17135988]

32. Birmaher B, Brent DA, Kolko D, et al. Clinical outcome after short-term psychotherapy for adolescents with major depressive disorder. Arch Gen Psychiatry. 2000; 57:29-36. [PubMed: 10632230]

33. Brent DA, Kolko DJ, Birmaher B, et al. Predictors of treatment efficacy in a clinical trial of three psychosocial treatments for adolescent depression. J Am Acad Child Adolesc Psychiatry. 1998; 37:906-914. [PubMed: 9735610]

34. Clarke G, Hops H, Lewinsohn PM, et al. Cognitive-behavioral group treatment of adolescent depression: Prediction of outcome. Behavior Therapy. 1992; 23:341-354.

35. Emslie GJ, Rush AJ, Weiberg WA, et al. Fluoxetine in child and adolescent depression: Acute and maintenance treatment. Depress Anxiety. 1998; 7:32-39. [PubMed: 9592630]

36. Mrazek, PJ.; Haggerty, RJ. Reducing risks for mental disorders: frontiers for preventive research. Washington (DC): National Academy Press; 1994.

37. Evans, DL.; Foa, EB.; Gur, RE., et al. Treating and preventing adolescent mental health disorders: what we know and what we don't know. New York: Oxford University Press; 2005.

38. Blueprint for change: research on child and adolescent mental health. Washington (DC): The National Institute of Mental Health, Office of Communications and Public Liaison; 2001. The National Advisory Mental Health Council Workgroup on Child and Adolescent Mental Health Intervention Development and Deployment. 
39. National Research Council, Institute of Medicine. Depression in parents, parenting, and children. Washington DC: National Academies Press; 2009. The etiology of depression; p. 73-118.

40. Evans, DL.; Foa, EB.; Gur, RE., et al. Treating and preventing adolescent mental health disorders: what we know and what we don't know. New York: Oxford University Press; 2005. Defining depression and bipolar disorder; p. 4-27.

41. Joorman, J.; Eugene, F.; Gotlib, IH. Parental depression: Impact on offspring and mechanisms underlying transmission of risk. In: Nolen-Hoeksema, S.; Hilt, LM., editors. Handbook of depression in adolescence. New York: Taylor \&amp; Francis Group; 2009. p. 441-472.

42. Beardslee WR, Podorefsky D. Resilient adolescents whose parents have serious affective and other psychiatric disorders: Importance of self-understanding and relationships. Am J Psychiatry. 1988; 145:63-69. [PubMed: 3337294]

43. Gilman SE, Kawachi I, Fitzmaurice GM, et al. Socioeconomic status in childhood and the lifetime risk of major depression. Int J Epidemiol. 2002; 31:359-367. [PubMed: 11980797]

44. Widom CS, Dumont K, Czaja SJ. A prospective investigation of major depressive disorder and comorbidity in abused and neglected children grown up. Arch Gen Psychiatry. 2007; 64:49-56. [PubMed: 17199054]

45. Horowitz JL, Garber J. The prevention of depressive symptoms in children and adolescents: a meta-analytic review. J Consult Clin Psychol. 2006; 74:401-415. [PubMed: 16822098]

46. Gillham JE, Shatte AJ, Freres DR. Preventing depression: a review of cognitive-behavioral and family interventions. Applied \&amp; Preventive Psychology. 2000; 9:63-88.

47. Kaslow NJ, Thompson MP. Applying the criteria for empirically supported treatments to studies of psychosocial interventions for child and adolescent depression. J Clin Child Psychol. 1998; 27:146-155. [PubMed: 9648032]

48. Spence SH, Sheffield JK, Donovan CL. Preventing adolescent depression: an evaluation of the problem solving for life program. J Consult Clin Psychol. 2003; 71:3-13. [PubMed: 12602420]

49. Spence SH, Sheffield JK, Donovan CL. Long-term outcome of a school-based, universal approach to prevention of depression in adolescents. J Consult Clin Psychol. 2005; 73:160-167. [PubMed: 15709843]

50. Shochet IM, Dadds MR, Holland D, et al. The efficacy of a universal school-based program to prevent adolescent depression. J Clin Child Psychology. 2001; 30:303-315.

51. Merry S, McDowell H, Wild CJ, et al. A randomized placebo-controlled trial of a school-based depression prevention program. J Am Acad Child Adolesc Psychiatry. 2004; 43:538-547. [PubMed: 15100560]

52. Horowitz JL, Garber J, Ciesla JA, et al. Prevention of depressive symptoms in adolescence: A randomized trial of cognitive behavioral and interpersonal prevention programs. J Consult Clin Psychol. 2007; 75:693-706. [PubMed: 17907851]

53. Clarke, G.; Gladstone, T.; DeBar, L., et al. Coping with stress course: prior effectiveness research, revision and improvements. Paper presented at the American Academy of Child and Adolescent Psychiatry; Boston. 2007.

54. Gillham, J.; Reivich, K.; Jaycox, L., et al. The Penn Resiliency Program. Philadelphia: University of Pennsylvania; 1990.

55. Gillham, J.; Brunwasser, SM.; Freres, DR. Preventing depression in early adolescence. In: Abela, JRZ.; Hankin, BL., editors. Handbook of depression in children and adolescents. New York: Guilford Press; 2008. p. 309-322.

56. Gillham JE, Hamilton J, Freres DR, et al. Preventing depression among early adolescents in the primary care setting: a randomized controlled study of the Penn Resiliency Program. J Abnorm Child Psychol. 2006; 34:203-219. [PubMed: 16741684]

57. Gillham JE, Reivich KJ, Freres DR, et al. School-based prevention of depression and anxiety symptoms in early adolescence: A pilot of a parent intervention component. School Psychology Quarterly. 2006; 21:323-348.

58. Cardemil EV, Reivich KJ, Seligman MEP. The prevention of depressive symptoms in low-income minority middle school students. Prevention \&amp; Treatment. 2002:5.

59. Cardemil EV, Reivich KJ, Beevers CG, et al. The prevention of depressive symptoms in lowincome minority children: Two-year follow-up. Behav Res Therapy. 2007; 45:313-327. 
60. Lewinsohn PM, Roberts R, Seeley J, et al. Adolescent psychopathology: II. Psychosocial risk factors for depression. J Abnorm Psychol. 1994; 103:302-315. [PubMed: 8040500]

61. Clarke G, Hawkins W, Murphy M, et al. Targeted prevention of unipolar depressive disorder in an at-risk sample of high school adolescents: a randomized trial of a group cognitive intervention. $\mathrm{J}$ Am Acad Child Adolesc Psychiatry. 1995; 34:312-321. [PubMed: 7896672]

62. Garber, J.; Clarke, G.; Brent, D., et al. Preventing depression in at-risk adolescents: design and sample characteristics. Paper presented at the American Academy of Child and Adolescent Psychiatry; Boston. 2007.

63. Weersing, R.; Brent, D.; Garber, J., et al. Prevention of depression in at-risk adolescents: outcome at 8 months. Paper presented at the American Academy of Child and Adolescent Psychiatry; Boston. 2007.

64. Compas BE, Champion JE, Reeslund KL, et al. Randomized controlled trial of a family cognitivebehavioral preventive intervention for children of depressed parents. J Consult Clin Psychol. 2009; 77:1007-1020. [PubMed: 19968378]

65. Beardslee WR, Gladstone TRG, Wright EJ, et al. A family-based approach to the prevention of depressive symptoms in children at risk: evidence of parental and child change. Pediatrics. 2003; 112:E99-E111.

66. Beardslee W, Salt $P$, Versage E, et al. Sustained change in parents receiving preventive interventions for families with depression. Am J Psychiatry. 1997; 154:510-515. [PubMed: 9090338]

67. Beardslee W, Versage E, Wright E, et al. Examination of preventive interventions for families with depression: evidence of change. Dev Psychopathol. 1997; 9:109-130. [PubMed: 9089127]

68. Beardslee WR, Wright EJ, Salt P, et al. Examination of children's responses to two preventive intervention strategies over time. J Am Acad Child Adolesc Psychiatry. 1997; 36:196-204. [PubMed: 9031572]

69. Beardslee W, Wright E, Gladstone T, et al. Long-term effects from a randomized trial of two public health preventive interventions for parental depression. J Fam Psychol. 2007; 21:703-713. [PubMed: 18179342]

70. Podorefsky DL, McDonald-Dowdell M, Beardslee WR. Adaptation of preventive interventions for a low-income, culturally diverse community. J Am Acad Child Adolesc Psychiatry. 2001; 40:879_ 886. [PubMed: 11501686]

71. D'Angelo EJ, Llerena-Quinn R, Shapiro R, et al. Adaptation of the preventive intervention program for depression for use with Latino families. Fam Process. Forthcoming.

72. Solantaus T, Toikka T. The effective family programme: preventative services for the children of mentally ill parents in Finland. Int J Ment Health Promot. 2005; 3:37-43.

73. Beardslee, W.; Hosman, C.; Solantaus, T., et al. Children of mentally ill parents: an opportunity for effective prevention all too often neglected. In: Hosman, C.; Jane-Llopis, E.; Saxena, S., editors. Prevention of mental disorders: effective interventions and policy options. Oxford: Oxford University Press; Forthcoming

74. Sandler, IN.; Wolchik, SA.; Davis, CH., et al. Correlational and experimental study of resilience for children of divorce and parentally-bereaved children. In: Luthar, SS., editor. Resilience and vulnerability: adaptation in the context of childhood adversities. New York: Cambridge University Press; 2003. p. 213-240.

75. Tein JY, Sandler IN, MacKinnon DP, et al. How did it work? Who did it work for? Mediation in the context of a moderated prevention effect for children of divorce. J Consult Clin Psychol. 2004; 72:617-624. [PubMed: 15301646]

76. Wolchik SA, West SG, Sandler IN, et al. An experimental evaluation of theory-based mother and mother-child programs for children of divorce. J Consult Clin Psychol. 2000; 68:843-856. [PubMed: 11068970]

77. Wolchik SA, Sandler IN, Millsap RE, et al. Six-year follow-up of preventive interventions for children of divorce: a randomized controled trial. J Am Acad Child Adolesc Psychiatry. 2002; 288:1874-1881.

78. Sandler, IN.; Ayers, TS.; Wolchik, SW., et al. Hosman, CMH.; Jane-Llopis, E.; Saxena, S., et al., editors. Prevention of mental disorders: an overview on evidence-based strategies and programs. 
London: World Health Organization; Children suffering from family disruption: separation, divorce and bereavement. Forthcoming

79. Sandler IN, Ayers TS, Romer AL. Fostering resilience in families in which a parent has died. J Palliat Med. 2002; 5:945-956. [PubMed: 12685543]

80. Sandler IN, Ayers TS, Wolchik SA, et al. The Family Bereavement Program: efficacy evaluation of a theory-based prevention program for parentally bereaved children and adolescents. J Consult Clin Psychol. 2003; 71:587-600. [PubMed: 12795581]

81. Sandler IN, Wolchik SA, Ayers TS. Resilience rather than recovery: a contextual framework on adaptation following bereavement. Death Stud. 2008; 32:59-73. [PubMed: 18652066]

82. Sandler, IN.; Wolchik, SA.; Ayers, TS., et al. Linking theory and intervention to promote resilience of children following parental bereavement. In: Stroebe, M.; Hansson, M.; Stroebe, W., et al., editors. Handbook of bereavement research: consequence, coping and care. Washington (DC): American Psychological Association; Forthcoming

83. Tein JY, Sandler IN, Ayers TS, et al. Mediation of the effects of the Family Bereavement Program on mental health problems of bereaved children and adolescents. Prev Sci. 2006; 7:179-195. [PubMed: 16775760]

84. Landback J, Prochaska M, Ellis J, et al. From prototype to product: Development of a primary care/internet based depression prevention intervention for adolescents (CATCH-IT). Community Ment Health J. 2009; 45:349-354. [PubMed: 19641992]

85. Van Voorhees BW, Fogel J, Pomper BE, et al. Adolescent dose and ratings of an internet-based depression prevention program: A randomized trial of primary care physician brief advice versus a motivational interview. Journal of Cognitive and Behavioral Psychotherapies. 2009; 9:1-19. [PubMed: 20694059]

86. Mufson, L.; Dorta, KP.; Moreau, D., et al. Interpersonal psychotherapy for depressed adolescents. 2nd ed.. New York: Guilford Press; 2004.

87. Mufson L, Dorta KP, Wickramaratne P, et al. A randomized effectiveness trial of interpersonal psychotherapy for depressed adolescents. Arch Gen Psychiatry. 2004; 61:577-584. [PubMed: 15184237]

88. Young JF, Mufson L, Davies M. Efficacy of interpersonal psychotherapy-adolescent skills training: an indicated preventive intervention for depression. J Child Psychol Psychiatry. 2006; 47:1254-1262. [PubMed: 17176380]

89. Avenevoli S, Merikangas KR. Implications of high-risk family studies for prevention of depression. Am J Prev Med. 2006; 31:s126-s135. [PubMed: 17175407]

90. Sims B, Nottelmann E, Koretz DS, et al. Prevention of depression in children and adolescents. Am J Prev Med. 2007; 32:451-455. Erratum. [PubMed: 17552079]

91. Brent D, Holder D, Kolko D, et al. A clinical psychotherapy trial for adolescent depression comparing cognitive, family and supportive therapy. Arch Gen Psychiatry. 1998; 54:877-885. [PubMed: 9294380]

92. Hammen C, Rudolph K, Weisz J, et al. The context of depression in clinic-referred youth: neglected areas in treatment. J Am Acad Child Adolesc Psychiatry. 1999; 38:64-71. [PubMed: 9893418]

93. Barrera M. Directions for expanding the prevention of depression in children and adolescents. Am J Prev Med. 2006; 31:S182-S183. [PubMed: 17175414] 


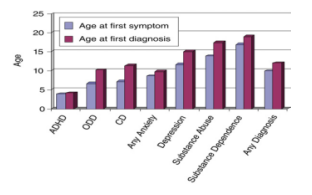

Figure 1.

Data suggests that early symptoms of disorder emerge a few years before full diagnostic criteria are met.

From National Research Council and Institute of Medicine. Prevention Committee. Preventing emotional and behavioral disorders among young people: progress and possibilities. [place unknown]: National Academies Press;2009. [6] 